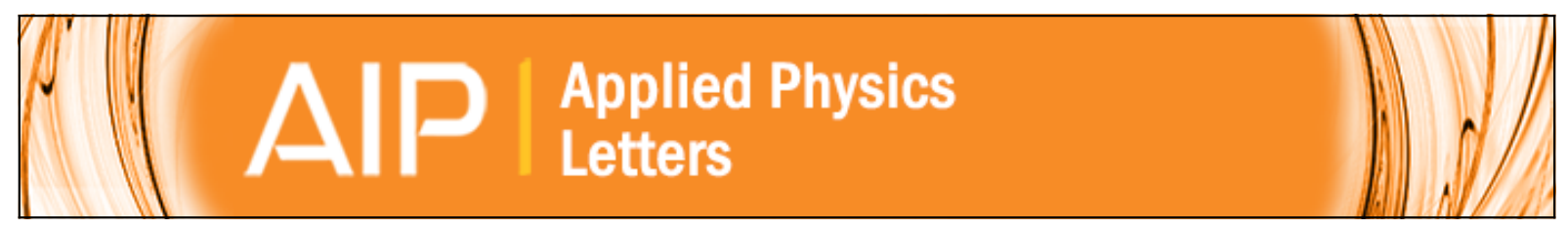

\title{
High performance thin film transistor with low temperature atomic layer deposition nitrogen-doped ZnO
}

S. J. Lim, Soon-ju Kwon, Hyungjun Kim, and Jin-Seong Park

Citation: Applied Physics Letters 91, 183517 (2007); doi: 10.1063/1.2803219

View online: http://dx.doi.org/10.1063/1.2803219

View Table of Contents: http://scitation.aip.org/content/aip/journal/apl/91/18?ver=pdfcov

Published by the AIP Publishing

\section{Articles you may be interested in}

Research Update: Atmospheric pressure spatial atomic layer deposition of ZnO thin films: Reactors, doping, and devices

APL Mat. 3, 040701 (2015); 10.1063/1.4916525

Low temperature atomic layer deposited $\mathrm{ZnO}$ photo thin film transistors

J. Vac. Sci. Technol. A 33, 01A105 (2015); 10.1116/1.4892939

Effect of Al concentration on Al-doped $\mathrm{ZnO}$ channels fabricated by atomic-layer deposition for top-gate oxide thin-film transistor applications

J. Vac. Sci. Technol. B 32, 041202 (2014); 10.1116/1.4880823

Schottky barrier source-gated $\mathrm{ZnO}$ thin film transistors by low temperature atomic layer deposition Appl. Phys. Lett. 103, 253503 (2013); 10.1063/1.4836955

Low temperature atomic layer deposited $\mathrm{Al}$-doped $\mathrm{ZnO}$ thin films and associated semiconducting properties J. Vac. Sci. Technol. B 30, 031210 (2012); 10.1116/1.4710519

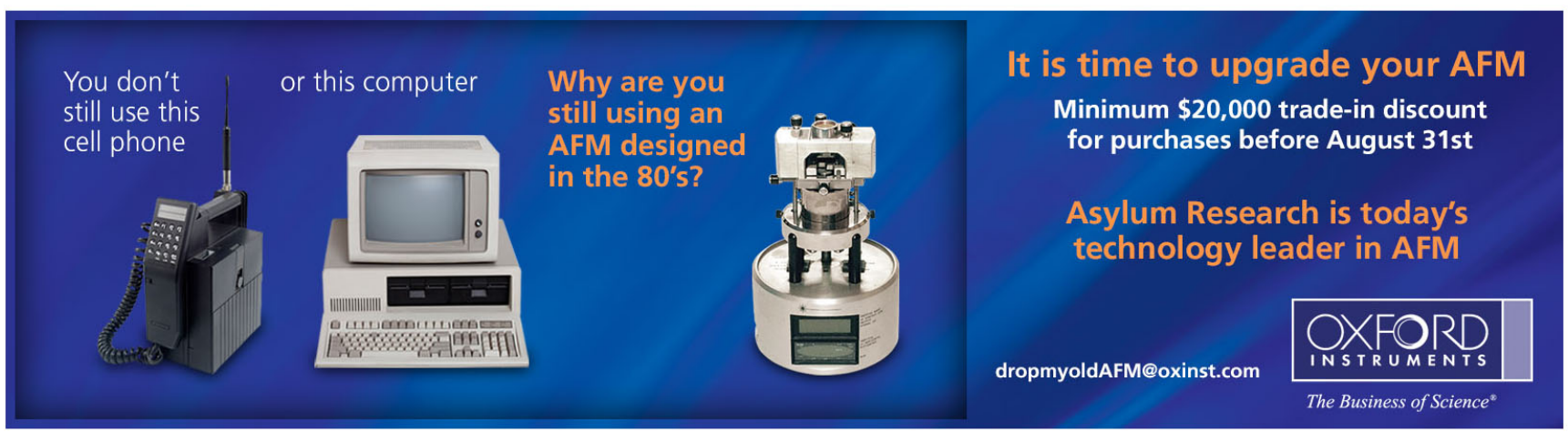




\title{
High performance thin film transistor with low temperature atomic layer deposition nitrogen-doped $\mathrm{ZnO}$
}

\author{
S. J. Lim, Soon-ju Kwon, and Hyungjun Kim ${ }^{\text {a) }}$ \\ Department of Materials Science and Engineering, Pohang University of Science and Technology \\ (POSTECH), San 31, Hyoja-dong, Nam-gu, Pohang 790-784, Republic of Korea \\ Jin-Seong Park \\ Display group, CRD center, Samsung SDI, Yongin-si 446-577, Republic of Korea
}

(Received 24 July 2007; accepted 6 October 2007; published online 2 November 2007)

\begin{abstract}
High performance thin film transistor (TFT) with atomic layer deposition (ALD) nitrogen doped $\mathrm{ZnO}(\mathrm{ZnO}: \mathrm{N})$ as an active layer is demonstrated. The electrical properties of $\mathrm{ZnO}$ thin films were effectively controlled by in situ nitrogen doping using $\mathrm{NH}_{4} \mathrm{OH}$ as a source for reactants. Especially, the electron concentration in $\mathrm{ZnO}$ was lowered to below $10^{15} \mathrm{~cm}^{-3}$. Good device characteristics were obtained from the inverted staggered type TFTs with $\mathrm{ZnO}: \mathrm{N}$ channel and $\mathrm{ALD} \mathrm{Al}_{2} \mathrm{O}_{3}$ gate insulator; $\mu_{\mathrm{sat}}=6.7 \mathrm{~cm}^{2} / \mathrm{V} \mathrm{s}, \quad I_{\text {off }}=2.03 \times 10^{-12} \mathrm{~A}, I_{\mathrm{on} / \mathrm{off}}=9.46 \times 10^{7}$, and subthreshold swing $=0.67 \mathrm{~V} /$ decade. The entire TFT fabrication processes were carried out at below $150{ }^{\circ} \mathrm{C}$, which is a favorable process for plastic based flexible display. (C) 2007 American Institute of Physics.
\end{abstract}

[DOI: $10.1063 / 1.2803219$ ]

The interests for future displays have been significantly increased to create electronic markets, including a flexible and transparent display. ${ }^{1}$ However, $a$-Si:H TFT has several limitations for future display applications such as low mobility (below $1.0 \mathrm{~cm}^{2} / \mathrm{V} \mathrm{s}$ ) (Refs. 1) and high photosensitivity. ${ }^{2}$ Although poly-Si TFT can solve these problems, the fabrication process requires high process temperature $\left(>250{ }^{\circ} \mathrm{C}\right)$ so $\mathrm{Si}$ based TFT cannot be used for transparent display. ${ }^{1}$ Recently, transparent oxide semiconductors have been proposed for the active channel layer of TFTs instead of silicon, especially for transparent display. ${ }^{1,3}$ Zinc oxide $(\mathrm{ZnO})$ is considered as an attractive candidate since it can be deposited even at room temperature with good electrical and optical properties. ${ }^{4}$

For practical applications of ZnO TFTs, the off current $\left(I_{\text {off }}\right)$ has to be low enough $\left(<10^{-11} \mathrm{~A}\right)$ since the high $I_{\text {off }}$ results in poor on/off ratio leading to problems in switching modulation. Moreover, the carrier mobility has to be large enough to provide stable operation of large-area displays at required video rate. ${ }^{5}$ Usually, the $\mathrm{ZnO}$ active layers for TFTs have been deposited by physical vapor deposition (PVD) such as direct current (dc) or radio frequency sputtering and pulsed laser deposition. ${ }^{3,6}$ Although TFTs with reasonable electrical properties have been reported, the lowest reported value of $I_{\text {off }}$ for room temperature PVD ZnO TFT devices has been usually higher than $10^{-10} \mathrm{~A}$. Besides, with upsizing of the display, the PVD may suffer from nonuniformity for large area. For example, the resistivity of PVD ZnO has been reported to be very sensitive to partial oxygen pressure during the deposition. ${ }^{6}$ Atomic layer deposition (ALD) produces films of high quality at a relatively low temperature, which makes it very attractive for the fabrication of the TFT on large area flexible substrate. Besides, another potential benefit of ALD process for the fabrication of the TFT is that all the essential components of transparent TFT, including gate, gate insulator, active channel, and source/drain layers, can be

\footnotetext{
${ }^{a)}$ Electronic mail: hyungjun@ postech.ac.kr
}

deposited by ALD. So far, just a few results have been reported on ALD ZnO TFT. ${ }^{7}$ Moreover, improvements in electrical properties are required since the ALD $\mathrm{ZnO}$ film has generally unsuitable electrical properties such as high electron carrier concentration $\left(>10^{18} / \mathrm{cm}^{3}\right)$ and high conductivity. ${ }^{8}$

In this study, we demonstrate the fabrication of high performance TFT devices using an ALD nitrogen doped $\mathrm{ZnO}$ film ( $\mathrm{ZnO}: \mathrm{N})$ as an active channel layer. The nitrogen doping was carried out in situ using ammonium hydroxide $\left(\mathrm{NH}_{4} \mathrm{OH}\right)$ as a source for reactants of ALD ZnO:N. By in situ nitrogen doping, the carrier concentration was controlled to proper level for active channel layer of the TFT devices. By employing $\mathrm{ALD} \mathrm{Al}_{2} \mathrm{O}_{3}$ at a low growth temperature $\left(T_{s}=150^{\circ} \mathrm{C}\right)$ as a gate insulator, high performance $\mathrm{ZnO}$ TFT devices were fabricated with high saturation mobility $\left(6.7 \mathrm{~cm}^{2} / \mathrm{V} \mathrm{s}\right)$, low $I_{\text {off }}\left(2.0 \times 10^{-12} \mathrm{~A}\right)$, high $I_{\text {on/off }}(9.5$ $\left.\times 10^{7}\right)$, and very low hysteresis $(<0.5 \mathrm{~V})$.

The undoped and nitrogen doped $\mathrm{ZnO}$ thin films were deposited on both glass (Corning 1737) and silicon (001) substrates by ALD with diethyl zinc (DEZ) as a precursor. For nitrogen doped $\mathrm{ZnO}$, diluted $\mathrm{NH}_{4} \mathrm{OH}$ solution was employed as a single source for reactants. The ALD has been carried out at various growth temperatures between 100 and $200{ }^{\circ} \mathrm{C}$. The film thicknesses were measured routinely by ellipsometer (Rudolph auto ELII). The chemical compositions and bonding states were determined by $\mathrm{x}$-ray photoelectron spectroscopy (XPS) (Escalab $220 \mathrm{iX}$ ). The microstructure of ALD ZnO was analyzed by x-ray diffraction (Rigaku Rint2500) and the surface roughness and lateral grain diameter were obtained from DI NanoScope IIIa Multimode atomic force microscopy (AFM). The optical transmittance measurements of the glass substrate, $\mathrm{ZnO} / \mathrm{Al}_{2} \mathrm{O}_{3}$ /glass, and $\mathrm{ZnO}: \mathrm{N} / \mathrm{Al}_{2} \mathrm{O}_{3}$ /glass samples were carried out by a Shimadzu UV1700 UV-Vis spectrometer in the wavelength range from 200 to $1100 \mathrm{~nm}$. The resistivity and Hall mobility of $\mathrm{ZnO}$ thin films were measured by Hall measurement system (Accent Optical Technologies HL5500PC). TFTs, which were staggered inverted type, with 


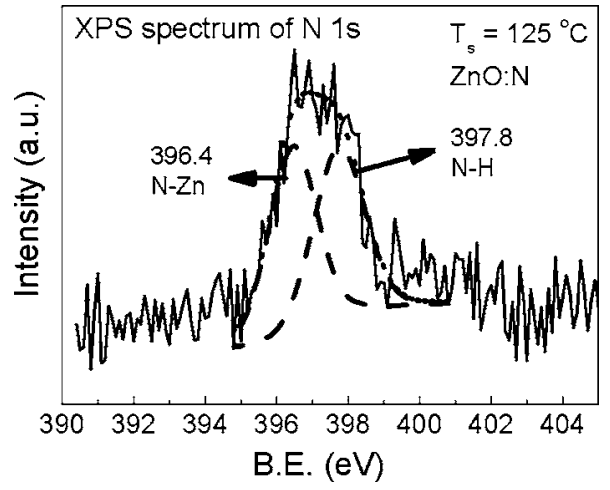

FIG. 1. XPS spectrum in $\mathrm{N} 1 s$ binding energy region of ALD ZnO:N at $T_{s}=125{ }^{\circ} \mathrm{C}$.

various channel widths $(W)$ and channel lengths $(L)$ were produced by conventional photolithography. As a first step of TFT fabrication, $100 \mathrm{~nm}$ thick Ti, prepared by dc magnetron sputtering at room temperature, was patterned by photolithography and wet etching to form gate electrode. Subsequently, $97 \mathrm{~nm}$ thick $\mathrm{ALD} \mathrm{Al}_{2} \mathrm{O}_{3}$ thin films was deposited as a gate insulator at $T_{s}=150{ }^{\circ} \mathrm{C}$ by using tri-methyl-aluminum and $\mathrm{H}_{2} \mathrm{O}$. The dielectric constant of the deposited $\mathrm{Al}_{2} \mathrm{O}_{3}$ films was 8.5 , which was obtained from separate $C-V$ measurements. ALD $\mathrm{ZnO}$ or $\mathrm{ZnO}: \mathrm{N}$ film as an active channel layer was also patterned by photolithography and wet etching. Finally, $100 \mathrm{~nm}$ thick Ti source/drain (S/D) layers were patterned by lift-off technique. Device characteristics, including transfer and output curves, were measured by semiconductor parameter analyzer (Keithley 4200) with three probes.

The growth rate of ALD $\mathrm{ZnO}$ at saturation conditions was $1.6 \AA /$ cycle, as reported previously. ${ }^{8}$ The growth rate was not affected by nitrogen doping. This good saturation in growth rates suggests that the ALD growth mode was achieved. The x-ray diffraction spectrum of undoped ALD $\mathrm{ZnO}$ film shows a predominant (002) diffraction peak with small (100) and (101) diffraction peaks, indicating the (002) preferred orientation. For ALD ZnO:N, however, the (002) peak intensity is reduced significantly, while the (100) and (101) peak intensities remain almost the same. (Data not shown) In addition, AFM measurements have shown that although the root mean square roughnesses of ALD ZnO and $\mathrm{ZnO}: \mathrm{N}$ films are almost the same $(2.3$ versus $2.8 \mathrm{~nm}$, respectively), the average grain diameter of $\mathrm{ZnO}$ is $66 \pm 14.1 \mathrm{~nm}$ and that of $\mathrm{ZnO}: \mathrm{N}$ is $51 \pm 6.4 \mathrm{~nm}$. Thus, nitrogen doping produces smaller grain size with more uniform grain size distribution.

Figure 1 shows the XPS spectrum of ALD ZnO:N film in the $\mathrm{N} 1 s$ binding energy region, deposited on $\mathrm{ALD} \mathrm{Al}_{2} \mathrm{O}_{3} / \mathrm{Si}$ substrate at $T_{s}=125^{\circ} \mathrm{C}$. The broad peak at around $397 \mathrm{eV}$ is deconvoluted to two peaks; one peak at $396.4 \mathrm{eV}$ from $\mathrm{N}-\mathrm{Zn}$ bond and the other peak at $397.8 \mathrm{eV}$ from $\mathrm{N}-\mathrm{H}$ bond. Thus, we infer that nitrogen atoms are incorporated as $\mathrm{Zn}-\mathrm{NH}_{x}$, which agrees with previous reports on nitrogen doped CVD $\mathrm{ZnO}$. ${ }^{9}$ Especially for our low temperature ALD process, most of nitrogen atoms are thought to be incorporated as $\mathrm{NH}_{x}$, since the thermal energy is not high enough to break all $\mathrm{N}-\mathrm{H}$ bonds of $\mathrm{NH}_{3}$ molecules. From the peak intensity, the nitrogen concentration in ALD ZnO:N film was estimated to be around 3.5 at. $\%$. Besides the nitrogen no other impurity such as carbon was detected.

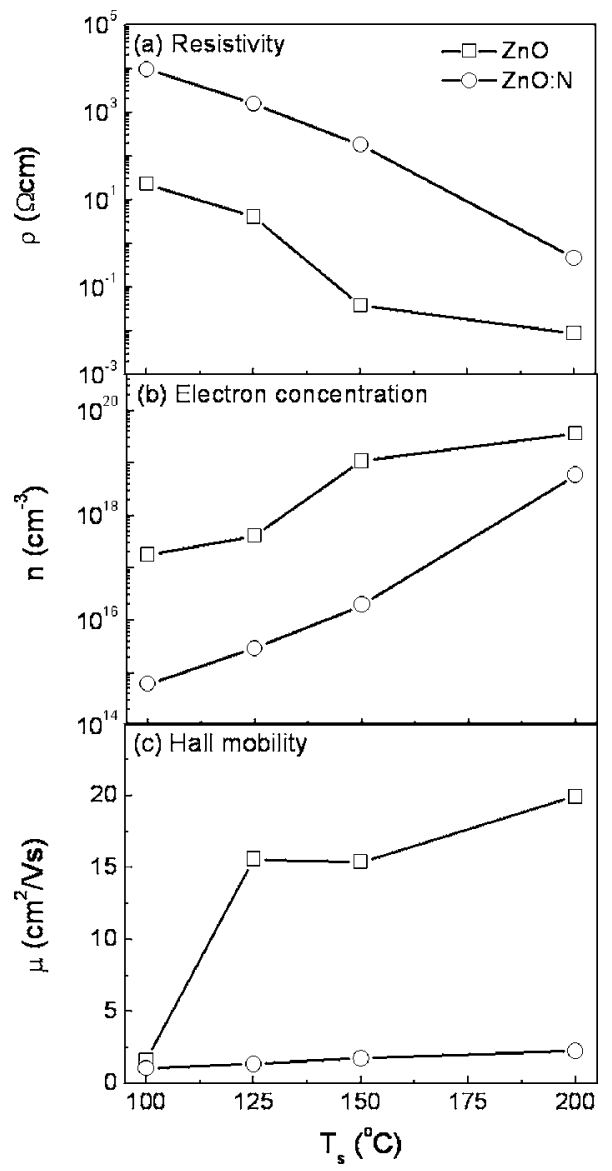

FIG. 2. Electrical properties of ALD $\mathrm{ZnO}$ and $\mathrm{ZnO}: \mathrm{N}$ thin films prepared at $T_{s}=100-200{ }^{\circ} \mathrm{C}$ (a) resistivity, (b) carrier concentration, and (c) Hall mobility.

The electrical properties of ALD ZnO film were significantly changed by nitrogen doping. Figure 2 shows the resistivity, Hall mobility, and carrier concentrations of ALD $\mathrm{ZnO}$ and $\mathrm{ZnO}: \mathrm{N}$ as a function of growth temperatures. For all the growth temperatures, the resistivity values increase almost by three orders of magnitude by nitrogen doping [Fig. 2(a)]. This large increase in resistivity is due to the significant decrease in carrier concentration, as shown in Fig. 2(b). Undoped ALD $\mathrm{ZnO}$ films show intrinsically $n$-type carrier conductivity with high carrier concentration up to 5 $\times 10^{19} \mathrm{~cm}^{-3}$. However, we obtained very low carrier concentration down to $6 \times 10^{14} \mathrm{~cm}^{-3}$ by nitrogen doping, especially at a low growth temperature. The mobility of ALD ZnO was reduced by nitrogen doping [Fig. 2(c)], probably due to the impurity scattering. ${ }^{10}$ Our XPS results indicate that most of nitrogen atoms are incorporated as $\mathrm{NH}_{x}$ due to the use of $\mathrm{NH}_{3}$ for $\mathrm{N}$ source and the low growth temperature. For this molecular configuration, the nitrogen is electrically passivated by $\mathrm{H}^{10}$ Due to this, we infer that although over 3.5 at. \% nitrogen has been incorporated, most of nitrogen atoms are electrically neutral and only a small portion of nitrogen atoms are consumed to compensate the $n$-type carriers. In addition, the transmittance measurements show that the transmittance of the ALD $\mathrm{ZnO}$ ( $80 \mathrm{~nm}$ thick)/ $\mathrm{Al}_{2} \mathrm{O}_{3} /$ glass sample is over $80 \%$ in the range of visible wave length (400-800 nm). Similarly, ALD ZnO:N (66 nm thick)/ $\mathrm{Al}_{2} \mathrm{O}_{3} /$ glass sample also shows high transmittance over $80 \%$ in the most of the range of visible wave length. 

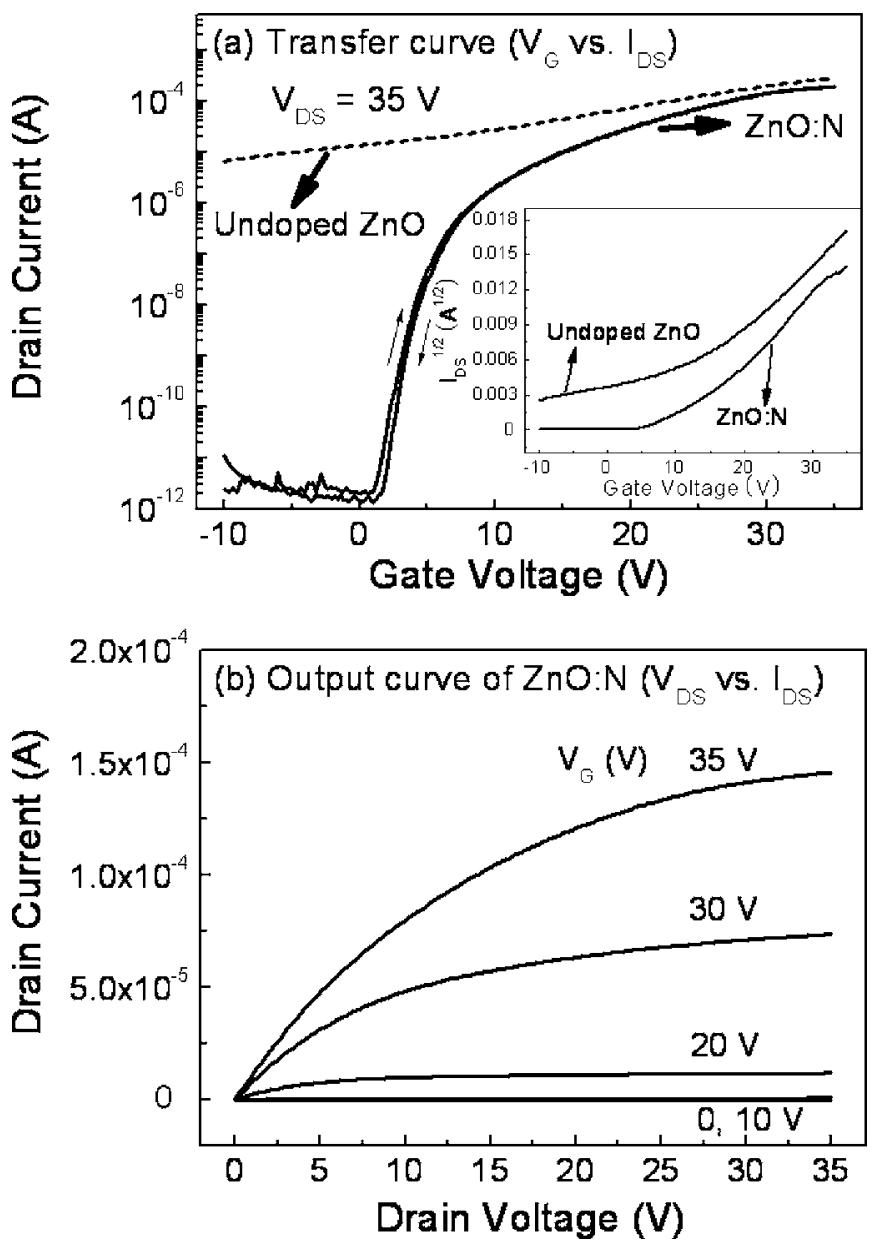

FIG. 3. (a) Transfer curves of TFTs with $\mathrm{ZnO}$ and $\mathrm{ZnO}: \mathrm{N}$ active layer, respectively. (The inset represents $V_{\mathrm{G}}$ vs root of $I_{\mathrm{DS}}$ curve). (b) Output curves on $\mathrm{ZnO}: \mathrm{N}$ TFT.

Inverted staggered type TFTs (with bottom gate and top contact) with various channel widths $(20-40 \mu \mathrm{m})$ and channel lengths $(20-100 \mu \mathrm{m})$ were fabricated using ALD $\mathrm{ZnO}$ and $\mathrm{ZnO}: \mathrm{N}$ deposited at $T_{s}=125^{\circ} \mathrm{C}$ as active layers and ALD $\mathrm{Al}_{2} \mathrm{O}_{3}$ deposited at $T_{s}=150{ }^{\circ} \mathrm{C}$ as a gate insulator. It should be noticed that all the device fabrication processes were carried out at below $150{ }^{\circ} \mathrm{C}$, as described in the experimental session. Figure 3(a) shows the transfer curves [gate voltage $\left(V_{\mathrm{G}}\right)$ versus drain current $\left.\left(I_{\mathrm{DS}}\right)\right]$ for the TFTs using ALD $\mathrm{ZnO}$ and $\mathrm{ZnO}: \mathrm{N}$ as active layers. The width, length, and source/drain and gate overlap of these TFT devices are 40,20 , and $5 \mu \mathrm{m}$, respectively. The thicknesses of ALD ZnO and $\mathrm{ZnO}: \mathrm{N}$ are 80 and $66 \mathrm{~nm}$, respectively, and the thickness of the ALD $\mathrm{Al}_{2} \mathrm{O}_{3}$ gate insulator is $97 \mathrm{~nm}$ for both cases. The transfer curves were measured under $35 \mathrm{~V}$ of drain voltage $\left(V_{D S}\right)$. As shown in Fig. 3(a), the TFT made with undoped $\mathrm{ZnO}$ as a channel does not show proper transistor characteristics. The general pinch-off and depletion phenomena were not observed during $V_{\mathrm{G}}$ sweeping. This behavior is expected when we consider that the undoped ALD ZnO has unacceptably high carrier concentration over $10^{17} / \mathrm{cm}^{3}$. On the contrary, ALD ZnO:N TFT shows typical behaviors of the $n$-channel enhancement mode TFT device. The output curves $\left(V_{\mathrm{DS}}\right.$ versus $\left.I_{\mathrm{DS}}\right)$ of $\mathrm{ZnO}: \mathrm{N}$ TFT measured at $V_{\mathrm{DS}}=0-35 \mathrm{~V}$ under various $V_{\mathrm{G}}(0-35 \mathrm{~V})$ are shown in Fig. 3(b). The out- put curves exhibit clear pinch-off and current saturation, indicating that the operation of this TFT device conforms to the standard field-effect transistor theory and the Fermi level in the channel is fully controlled by the gate and drain bias.

The threshold voltage $\left(V_{\mathrm{th}}\right)$ and the saturation mobility $\left(\mu_{\text {sat }}\right)$ were obtained by fitting the straight line of the square root of $I_{\mathrm{DS}}$ versus $V_{\mathrm{G}}$ [shown as an inset in Fig. 3(a)]. The $\mu_{\text {sat }}$ was about $6.7 \mathrm{~cm}^{2} / \mathrm{V} \mathrm{s}$ and $V_{\text {th }}$ was $4.1 \mathrm{~V}$, showing that the $\mathrm{ZnO}: \mathrm{N}$ TFT operated in the enhancement mode, leading to the decrease in the power consumption. For the various channel widths and lengths, no significant difference in device performances was observed. Also, a short channel effect was not observed for the channel lengths down to $20 \mu \mathrm{m}$. More importantly, excellent off-current $\left(I_{\text {off }}\right) \quad(2.03$ $\left.\times 10^{-12} \mathrm{~A}\right)$ and on/off ratio $\left(I_{\text {on/off }}\right)\left(9.46 \times 10^{7}\right)$ were obtained for the ALD ZnO:N TFTs, which are comparable to $a-\mathrm{Si}: \mathrm{H}$ or poly-Si TFT. Although higher mobility values were obtained for PVD based ZnO TFTs in several previous reports, ${ }^{1,3,6,11}$ they have limitations in the practical applications due to high $I_{\text {off }}$ current $\left(>10^{-10} \mathrm{~A}\right)$. Moreover, the hysteresis of ALD ZnO:N TFT was $<0.5 \mathrm{~V}$, indicating that the gate insulator and active layer have very small charge traps $\left(D_{t} \sim C_{i} \Delta V_{\mathrm{G}} / q=2.49 \times 10^{11} / \mathrm{cm}^{2}\right)$. In addition, the subthreshold swing of the device was $0.67 \mathrm{~V} /$ decade, which is relatively small, compared to other previous reports. ${ }^{3,6}$

All these results indicate that the nitrogen doping to ALD $\mathrm{ZnO}$ drastically improves the electrical properties as an active channel layer of TFT devices and is expected to be a valuable technique for the fabrication of the practical and stable TFT devices. Due to the many great benefits of ALD including a low growth temperature and large area uniformity, ALD based thin films should be considered as a promising candidate for the next generation display device fabrication. Additionally, we expect that nitrogen-doping technique during ALD process proposed in the current study would find various applications in many other materials system.

This work was supported by POSTECH Core Research Program, Korean Research Foundation Grant funded by the Korean Government (MOEHRD) (Grant No. KRF-2005005-J13102), and Samsung SDI.

${ }^{1}$ K. Nomura, H. Ohta, A. Takagi, T. Kamiya, M. Hirano, and H. Hosono, Nature (London) 432, 488 (2004).

${ }^{2}$ H. Kakinura, Phys. Rev. B 39, 10473 (1989).

${ }^{3}$ E. Fortunato, P. Barquinha, A. Primentel, A. Goncalves, A. Marques, L. Pereira, and R. Martins, Adv. Mater. (Weinheim, Ger.) 17, 590 (2005).

${ }^{4}$ S. J. Pearton, D. P. Norton, K. Ip, Y. W. Heo, and T. Steiner, Superlattices Microstruct. 34, 3 (2003).

${ }^{5}$ M. Stewart, R. S. Howell, L. Pires, and M. K. Hatalis, IEEE Trans. Electron Devices 48, 846 (2001).

${ }^{6}$ P. F. Carcia, R. S. Mclean, M. H. Reilly, and G. Nunes, Jr., Appl. Phys. Lett. 82, 1119 (2003).

${ }^{7}$ C.-S. Hwang, S.-H. K. Park, J.-I. Lee, S. M. Chung, Y. S. Yang, L.-M. Do, and H. Y. Chu, SID Int. Symp. Digest Tech. Papers 28, 237 (2006).

${ }^{8}$ S. J. Lim, S.-J. Kwon, and H. Kim, "ZnO thin films prepared by atomic layer deposition and rf sputtering as an active layer for thin film transistor," Thin Solid Films (to be published).

${ }^{9}$ K. Minegishi, Y. Koiwai, Y. Kikuchi, K. Yano, M. Kasuga, and A. Shimizu, Jpn. J. Appl. Phys., Part 2 36, L1453 (1997).

${ }^{10}$ J. Lu, Y. Zhang, Z. Ye, L. Wang, B. Zhao, and J. Huang, Mater. Lett. 57, 3311 (2003).

${ }^{11}$ H. Q. Chiang, J. F. Wager, R. L. Hoffman, J. Jeong, and D. A. Keszler, Appl. Phys. Lett. 86, 013503 (2005). 